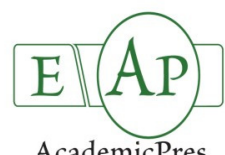

\title{
Effects of Saline and Alkaline Stresses on Growth and Physiological Changes in Oat (Avena sativa L.) Seedlings
}

\author{
Zhanwu GAO ${ }^{1,2}$, Jiayu HAN ${ }^{1}$, Chunsheng MU ${ }^{1 *}$, Jixiang LIN ${ }^{3 *}$, \\ Xiaoyu LI ${ }^{4}$, Lidong LIN $^{5}$, Shengnan SUN ${ }^{1}$ \\ ${ }^{1}$ Key Laboratory of Vegetation Ecology of Ministry of Education, Institute of Grassland Science, \\ Northeast Normal University, Changchun, 130024, China; mucs821@gmail.com ("corresponding author) \\ ${ }^{2}$ Department of Geography, Baicheng Normal College, Baicheng, 137000, China \\ ${ }^{3}$ Alkali Soil Natural Environmental Science Center, Northeast Forestry University, Key Laboratory of Saline-Alkali Vegetation Ecology \\ Restoration in Oil Field, Ministry of Education, Harbin, 150040, China; jixiang851012@gmail.com ("corresponding author) \\ ${ }^{4}$ Key Laboratory of Wetland Ecology and Environment, Northeast Institute of Geography and Agroecology, \\ Chinese Academy of Science, Changchun 130012, China \\ ${ }^{5}$ Dongtou Fisheries Science and Technology Research Institute, Dongtou, 325700, China
}

\begin{abstract}
Two neutral salts $\left(\mathrm{NaCl}\right.$ and $\left.\mathrm{Na}_{2} \mathrm{SO}_{4}\right)$ and alkaline salts $\left(\mathrm{NaHCO}_{3}\right.$ and $\left.\mathrm{Na}_{2} \mathrm{CO}_{3}\right)$ were both mixed in 2:1 ratio, and the effects of saline and alkaline stresses on growth and physiological changes in oat seedlings were explored. Result showed that biomass, water content and chlorophyll content decreased while cell membrane permeability significantly increased under alkaline stress. Saline stress did not have obvious effect on $\mathrm{pH}$ value in tissue fluids of shoot and root, but alkaline stress increased $\mathrm{pH}$ value in root tissue fluid. The contents of $\mathrm{Na}^{+}, \mathrm{Na}^{+} / \mathrm{K}^{+}, \mathrm{SO}_{4}^{2-}$ increased more, and $\mathrm{K}^{+}, \mathrm{NO}_{3}^{-}, \mathrm{H}_{2} \mathrm{PO}_{4}^{-}$decreased more under alkaline stress, the $\mathrm{Cl}^{-}$content increased obviously under saline stress but had little change under alkaline stress. The increments of proline and organic acid were both greater under alkaline stress, but organic acid content kept the same level under saline stress. Alkaline stress caused more harmful effects on growth and physiological changes in oat seedlings especially broke the $\mathrm{pH}$ stability in root tissue fluid. Physiological adaptive mechanisms of oat seedlings under saline stress and alkaline stress were different, which mainly took the way of accumulating organic acid under alkali stress but accumulating $\mathrm{Cl}^{-}$under saline stress.
\end{abstract}

Keywords: alkali stress, chlorophyll, organic acid, proline, salt stress

\section{Introduction}

As saline soil widely distributes in more than 100 countries, and covers about $10 \%$ of arable area over the world, soil salinization becomes one of the environmental problems over the world. Cations of soluble salts in saline-alkaline soil mainly include $\mathrm{Na}^{+}, \mathrm{Ca}^{2+}, \mathrm{Mg}^{2+}$ and $\mathrm{K}^{+}$, anions mainly include $\mathrm{Cl}^{-}, \mathrm{SO}_{4}{ }_{4}^{2-}, \mathrm{HCO}_{3}{ }^{-}, \mathrm{CO}_{3}{ }^{2-}$ and $\mathrm{NO}_{3}^{-}$(Tannic 1990). The characteristic of saline-alkaline soil in Northeast China is that $\mathrm{Na}^{+}$is the main cations and $\mathrm{Cl}^{-}, \mathrm{SO}_{4}{ }^{2-}, \mathrm{HCO}_{3}{ }^{-}$and $\mathrm{CO}_{3}{ }^{2-}$ are the main anions (Yang et al., 2007, 2008). Once soil contains alkaline salt such as $\mathrm{NaHCO}_{3}$ and $\mathrm{Na}_{2} \mathrm{CO}_{3}, \mathrm{pH}$ value of the soil will increase. At this time, plants suffer from not only saline stress but also alkaline stress caused by high $\mathrm{pH}$. The damage effect of alkaline stress caused by alkali salts such as $\mathrm{NaHCO}_{3}$ and $\mathrm{Na}_{2} \mathrm{CO}_{3}$ on plant is more obvious than that of saline stress caused by neutral salts such as $\mathrm{NaCl}$ and $\mathrm{Na}_{2} \mathrm{SO}_{4}$ (Yang et al., 2009). Soil salinization and alkalization frequently co-occur such as in the west Songnen plain of
Northeast China, soil salinization and alkalization in grassland and farmland becomes more seriously, which cause losses in agricultural productivity and pose an ecological crisis for humans.

Oat (Avena sativa L.) is an annual crop, which belongs to the family of Poaceae. It is a world-wide cultivation crop and mainly distribute in temperate latitudes of the Northern Hemisphere. Oat has no strict requirements for cultivation soil, so it can be usually planted in various kinds of soil. Due to the good saline-alkaline tolerance, oat grew better than other crops when planted in semiarid and saline-alkaline soils, such as wheat. Up to now, most researches focus on crops e.g. sunflower (Shi and Sheng, 2005), and grasses such as Leymus chinensis and Puccinellia distans (Shi and Sheng, 1998; Li et al., 2004) and make progresses on the growth, physiological response mechanisms and adaptive strategies of these crops/grasses to saline and alkaline stresses. However, there was little research on the growth and saline-alkaline tolerance 
of oat to saline-alkaline stresses. In order to study the saline or alkaline tolerance of oat seedlings, two neutral salts $(\mathrm{NaCl}$ and $\left.\mathrm{Na}_{2} \mathrm{SO}_{4}\right)$ and two alkaline salts $\left(\mathrm{NaHCO}_{3}\right.$ and $\left.\mathrm{Na}_{2} \mathrm{CO}_{3}\right)$ were mixed to simulate different saline-alkaline stress conditions to treat on oat seedlings, and compared the effect of saline and alkaline stresses on growth and physiological changes of this species.

\section{Materials and methods}

\section{Plant materials}

Oat adopted in this experiment is new cultivar 'Baiyan 2' which cultivated by Baicheng Agricultural Academy in Jilin Province of China. Uniform and full seeds were sown in 20-cm diameter plastic opened pots containing washed sands. After germinated, each pot was fully irrigated by Hoagland's nutrient solution daily. Each pot contained 20 seedlings before treatment. All pots were placed outdoors and protected from rain.

\section{Saline and alkaline stresses treatment}

Two neutral salts $\mathrm{NaCl}$ and $\mathrm{Na}_{2} \mathrm{SO}_{4}$ and two alkaline salts $\mathrm{NaHCO}_{3}$ and $\mathrm{Na}_{2} \mathrm{CO}_{3}$ were both mixed in a 2:1 molar ratio, respectively. Six concentration treatments were applied to both groups: 48, 72, 96, 120, 144 and $168 \mathrm{mM}$, which simulated 12 different saline and alkaline stresses gradients $(\mathrm{pH}$ values were from 7.03 to 7.29 in salt stress, and were from 9.84 to 10.69 in alkaline stress).

When oat seedlings were 4 weeks old, 39 pots with uniform growth were selected and divided into 13 groups, with 3 pots per group. Each pot was a single replicate with three replicated per group. One group was for comparison and the other 12 groups were used for different treatments. Stress treatments were applied daily at 17:00 with $500 \mathrm{~mL}$ of nutrient solutions containing the appropriate stress salts. The comparison group was fully irrigated only by Hoagland's nutrient solution. All treatments were continuously treated for 9 days.

\section{Measurement of growth and physiological indexes}

Livability: livability $=\mathrm{n} / \mathrm{N}$ (' $\mathrm{n}$ ' represented the number of viable plants after the 9-day treatment, and ' $\mathrm{N}$ ' was the total number of tested plants).

Biomass: Samples were harvested at 7:00 the next morning of the last treatment. All plants in each pot were taken out carefully and cleaned by distilled water. After absorbing the water on the surface of seedlings by absorbent paper, 10 seedlings per pot were taken for measuring plant height and fresh weight $(\mathrm{FW})$; and then were oven-dried at $105^{\circ} \mathrm{C}$ for 15 min and then dried at $80{ }^{\circ} \mathrm{C}$ to a constant weight, the dry weight (DW) was recorded. The rest materials were dried for measuring other indexes.

Tissue $\mathrm{pH}: 5 \mathrm{~g}$ fresh sample of shoot and root were taken and fully cleaned by distilled water for 3 times, after absorbing surface water by filter paper, the tissue fluid was extruded by injector, instantly measuring $\mathrm{pH}$ value by digital $\mathrm{pH}$ meter (PHSI-4A type).

Water content: water content=FW-DW (FW was the fresh weight of plants; DW was dry weight of plants).

Chlorophyll content: After 9 days of stress treatment, fresh functional leaves were collected from the plants and cut into small segments to determine the concentration of chlorophyll $a$ and $b$. Chlorophyll was extracted from $0.5 \mathrm{~g}$ fresh samples with
$80 \%$ acetone solution. The extracted solution was centrifuged. The optical density (OD value) of the diluted solution was measured at 663 and $645 \mathrm{~nm}$. The concentrations of chlorophyll $a\left(C_{a}\right)$ and $b\left(C_{b}\right)$ were calculated using formula (1) and (2), respectively.

$$
\begin{aligned}
& C a=0.0127 \mathrm{OD}_{663}-0.00269 \mathrm{OD}_{645} \\
& C b=0.0229 \mathrm{OD}_{645}-0.00468 \mathrm{OD}_{663}
\end{aligned}
$$

Leaf conductivity: membrane permeability is reflected by the relative electrical conductivity, ELR was determined as described by Lutts et al. (1996), which was defined as the ratio of the electrical conductivity of leaves with intact membranes (S1) to those with membranes destroyed by boiling water treatment (S2). A fresh leaf $(1.0 \mathrm{~g})$ was cut into $1 \mathrm{~cm}$ long segments, divided equally, and placed in 2 vials with $20 \mathrm{~mL}$ deionized water each. One vial was incubated at $25^{\circ} \mathrm{C}$ on a rotary shaker for $2 \mathrm{~h}$, and the electrical conductivity of the solution (S1) was then determined using a conductivity gauge. The other vial was placed in boiling water for $5 \mathrm{~min}$, and the electrical conductivity of the solution (S2) was measured after equilibration to $25^{\circ} \mathrm{C}$.

$$
E L R=S_{1} / S_{2}
$$

Content of dissociative proline: Free proline was assayed by the acid-ninhydrin method. The dried shoot tissue samples $(0.1 \mathrm{~g})$ were homogenized in $10 \mathrm{ml}$ of $3 \%$ sulfosalicylic acid and then filtered. The filtrate $(2 \mathrm{~mL})$ was mixed with $2 \mathrm{ml}$ acidninhydrin and $2 \mathrm{~mL}$ of glacial acetic acid in a test tube. The mixture was placed in a water bath for $1 \mathrm{~h}$ at $100{ }^{\circ} \mathrm{C}$. The reaction mixture was extracted with $4 \mathrm{ml}$ toluene and the chromophore containing toluene was aspirated, cooled to room temperature, and the absorbance was measured at 520 $\mathrm{nm}$ with Spectrometer.

Organic acid: Organic acid was measured by DX-300 type ionic chromatographic system (DIONEX, Sunnyvale, USA), and the measurement conditions were as follows: ICE-AS6 analytical column, CDM-II electric conductivity detector, AMMS-ICE II interference suppressor, mobile phase was 0.4 $\mathrm{mM}$ perfluorobutyric acid, flow speed was $1.0 \mathrm{~mL} / \mathrm{min}$, column temperature was $20^{\circ} \mathrm{C}$, sample size was $50 \mu \mathrm{L}$ (Zhang and $\mathrm{Mu}, 2009)$. The total content of organic acid in the experiment was summation of all organic acid components which could be measured, including citric acid, malic acid and methanoic acid, lactic acid, acetic acid, succinic acid and oxalic acid.

Inorganic ion: Three cations, $\mathrm{Na}^{+}, \mathrm{K}^{+}$and dissociative $\mathrm{Ca}^{2+}$ were determined by atomic absorption spectrophotometer (TAS-990, Purkinje General, Beijing). Three anions, $\mathrm{NO}_{3}, \mathrm{Cl}$, $\mathrm{SO}_{4}^{2-}$ were determined by DX-300 ionic chromatographic system (DIONEX, Sunnyvale, USA), and the measurement conditions were as follows: AS4A-SCion exchange column, CD M-II electric conductivity detector, mobile phase was $\mathrm{Na}_{2} \mathrm{CO}_{3} / \mathrm{NaHCO}_{3}=1.7 / 1.8 \mathrm{mM}$. $\mathrm{H}_{2} \mathrm{PO}_{4}$ was determined by molybdenum blue staining method.

\section{Data analysis}

Statistical tests were performed using SPSS 13.0 and by one-way ANOVAS (SPSS Inc, Chicago, IL, USA), the significance level was set at $P \leq 0.05$. 
359

\section{Results}

\section{Effects on the growth of oat seedlings}

Under saline stress, the livability of seedlings at all salinity was $100 \%$. It did not reach seedling lethal degree even though at the highest salinity $(168 \mathrm{mM}, \mathrm{pH}$ was 7.29). Under alkaline stress, the livability decreased obviously when the salinity was more than $96 \mathrm{mM}$ and $\mathrm{pH}$ was over $9.96(P<0.01)$. When salinity was more than 144 $\mathrm{mM}$ and $\mathrm{pH}$ was over 10.39 , most seedlings were dead, and the livability was only $18 \%(P<0.01$, Fig. $1 \mathrm{~A})$.

Biomass of the seedlings did not change when salinity was less than $48 \mathrm{mM}$ and $\mathrm{pH}$ was less than 7.03 , but gradually and visibly decreased when the salinity was more than $72 \mathrm{mM}$ and $\mathrm{pH}$ was more than 7.12. Under alkaline stress, the greater stress concentration was, the lower biomass was, and the decrements were much larger than that in saline stress $(P<0.05$, Fig. $1 \mathrm{~B})$.

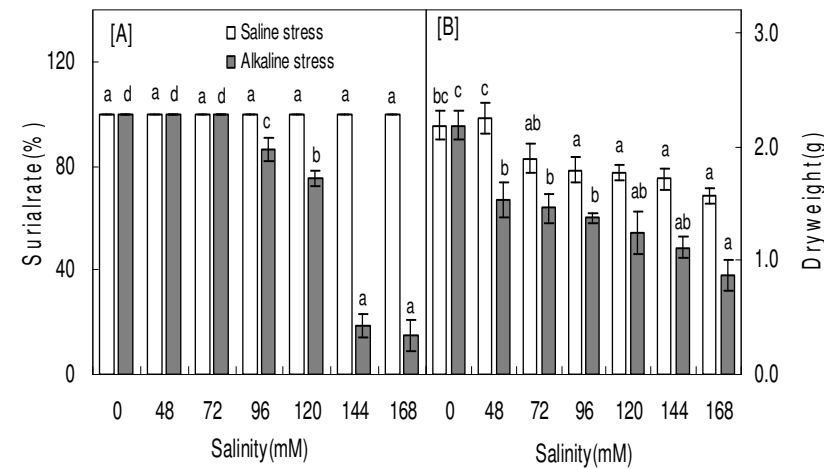

Fig. 1. Effect of salt and alkali stresses on survival/livability (A) and biomass (B) of oat seedlings, the 4 week-old oat seedlings were

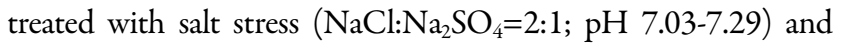
alkali stress $\left(\mathrm{NaHCO}_{3}: \mathrm{Na}_{2} \mathrm{CO}_{3}=2: 1 ; \mathrm{pH}\right.$ 9.84-10.61) for 9 days, the values are means $( \pm \mathrm{SE})$ of triplicate samples

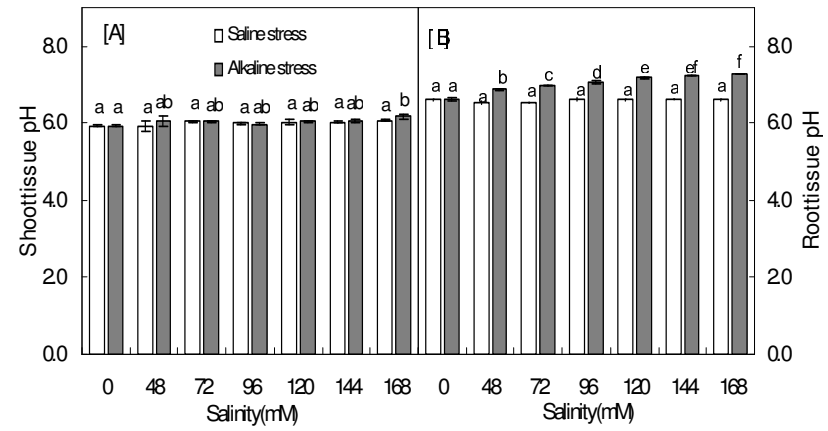

Fig. 2. Effect of salt and alkali stresses on shoot (A) and root (B) pH values of oat seedlings, the 4 week-old oat seedlings were treated with salt stress $\left(\mathrm{NaCl}_{2} \mathrm{Na}_{2} \mathrm{SO}_{4}=2: 1 ; \mathrm{pH}\right.$ 7.03-7.29) and alkali stress $\left(\mathrm{NaHCO}_{3}: \mathrm{Na}_{2} \mathrm{CO}_{3}=2: 1 ; \mathrm{pH} 9.84-10.61\right)$ for 9 days, the values are means $( \pm \mathrm{SE})$ of triplicate samples

Effects on tissue pH, chlorophyll content, cell membrane permeability and water content

The $\mathrm{pH}$ value of tissue fluid from aboveground tissues was not affected by saline stress and alkaline stress (Fig. 2 A). The $\mathrm{pH}$ value of root tissue fluid kept stably under saline stress, but increased obviously with the increasing alkaline stress concentration $(P<0.05$, Fig. 2 B).

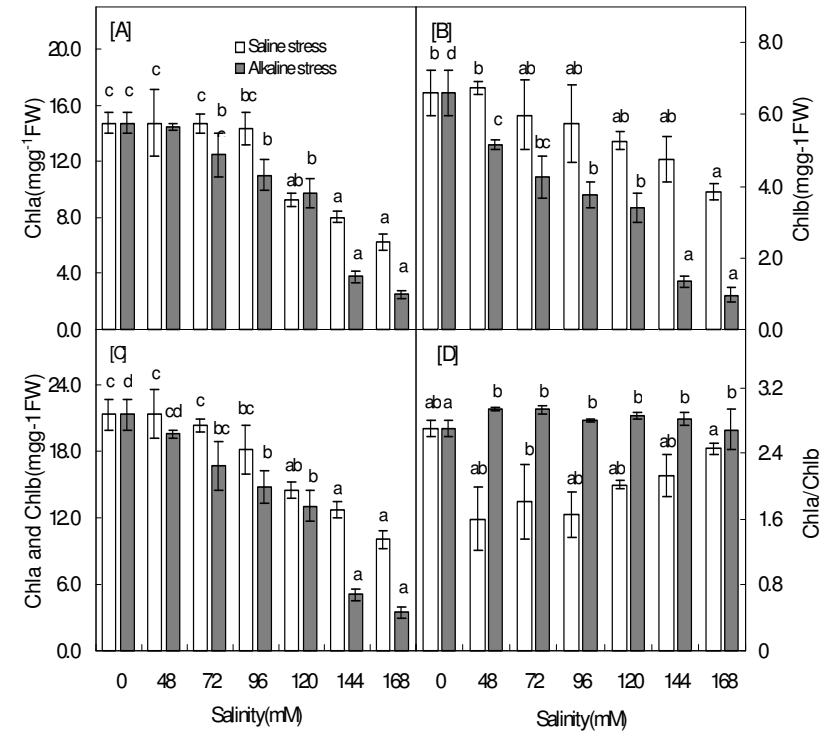

Fig. 3. Effect of salt and alkali stresses on chlorophyll contents of oat seedlings, the 4 week-old oat seedlings were treated with salt stress $\left(\mathrm{NaCl}: \mathrm{Na}_{2} \mathrm{SO}_{4}=2: 1 ; \mathrm{pH} 7.03-7.29\right)$ and alkali stress $\left(\mathrm{NaHCO}_{3}: \mathrm{Na}_{2} \mathrm{CO}_{3}=2: 1 ; \mathrm{pH}\right.$ 9.84-10.61) for 9 days, the values are means $( \pm \mathrm{SE})$ of triplicate samples

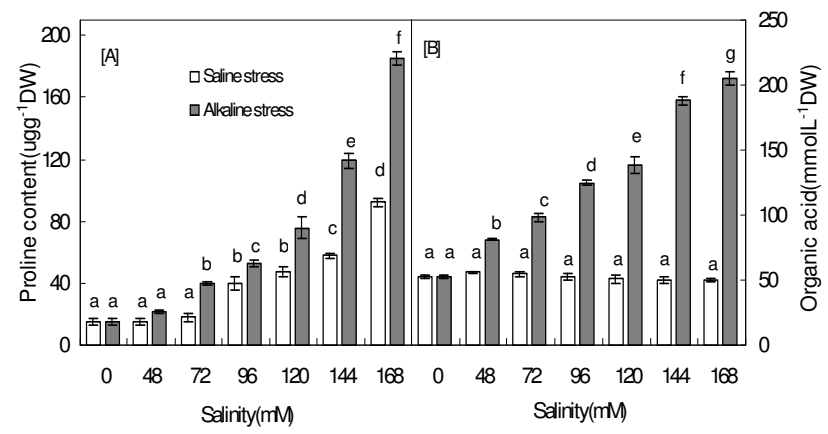

Fig. 4. Effect of salt and alkali stresses on proline (A) and organic acids (B) of oat seedlings, the 4 week-old oat seedlings were treated with salt stress $\left(\mathrm{NaCl}: \mathrm{Na}_{2} \mathrm{SO}_{4}=2: 1 ; \mathrm{pH}\right.$ 7.03-7.29) and alkali stress $\left(\mathrm{NaHCO}_{3}: \mathrm{Na}_{2} \mathrm{CO}_{3}=2: 1 ; \mathrm{pH} 9.84-10.61\right)$ for 9 days, the values are means $( \pm \mathrm{SE})$ of triplicate samples

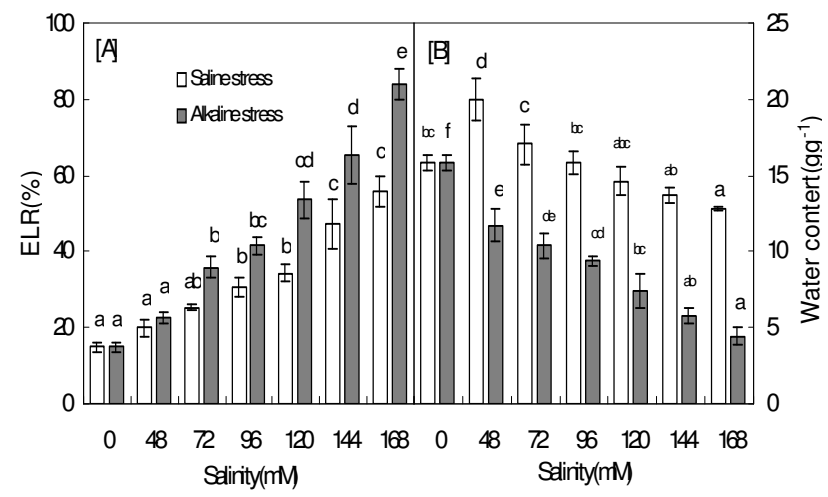

Fig. 5. Effect of salt and alkali stresses on bio-membrane permeability (A) and water content (B) of oat seedlings, the 4 week-old oat seedlings were treated with salt stress $\left(\mathrm{NaCl}_{2} \mathrm{Na}_{2} \mathrm{SO}_{4}=2: 1 ; \mathrm{pH} 7.03\right.$ 7.29) and alkali stress $\left(\mathrm{NaHCO}_{3}: \mathrm{Na}_{2} \mathrm{CO}_{3}=2: 1 ; \mathrm{pH}\right.$ 9.84-10.61) for 9 days, the values are means $( \pm \mathrm{SE})$ of triplicate samples 
With the increasing salinity under saline and alkaline stress, the total amount of chlorophyll $a$, chlorophyll $b$ and chlorophyll was visibly decreased, and the decrement was higher under alkaline stress than that under saline stress $(P<0.05$, Fig. $3 \mathrm{~A}, \mathrm{~B}, \mathrm{C})$; the cell membrane permeability was visibly increased, and the increment was higher under alkaline stress than that under saline stress $(P<0.05$, Fig. 5 A).

The water content was significantly higher than the comparison group when the salinity was lower than 72 $\mathrm{mM}$ and $\mathrm{pH}$ was less than 7.06 and then visibly decreased when the stress concentration was higher than $96 \mathrm{mM}$ and $\mathrm{pH}$ was more than $7.14(P<0.05$, Fig. $5 \mathrm{~B})$.

\section{Effects on internal inorganic ions and organic solutes}

With the increasing salinity, the $\mathrm{Na}^{+}$contents were obviously increased under both stresses. The accumulation amount of $\mathrm{Na}^{+}$under alkaline stress was 46.5 times than that of the comparison group at the highest salinity, which was 1.8 times higher than that under saline stress (Fig. 6A). The $\mathrm{K}^{+}$contents was visibly decreased $(P<0.05$, Fig. $6 \mathrm{~B})$, but the amount of $\mathrm{Ca}^{2+}$ was increased significantly, and the increment of $\mathrm{Ca}^{2+}$ was greater under saline stress than that under alkaline stress (Fig. 6C). The ratio of $\mathrm{Na}^{+} / \mathrm{K}^{+}$was visibly increased with the increasing salinity and alkalinity, which was 4.7 times under alkaline stress than that under saline stress at the highest stress concentration (Fig. 6D).

With increasing salinity, the $\mathrm{Cl}^{-}$contents was obviously increased under saline stress $(P<0.01)$, but changed a little under alkaline stress. Compared with controls, $\mathrm{Cl}^{-}$content was 5.5 times higher at the highest salinity than that of the control (Fig. 7A). $\mathrm{SO}_{4}^{2-}$ contents increased in both saline and alkaline stresses, and the increment in alkaline stress was greater than that in saline stress (Fig. 7B).

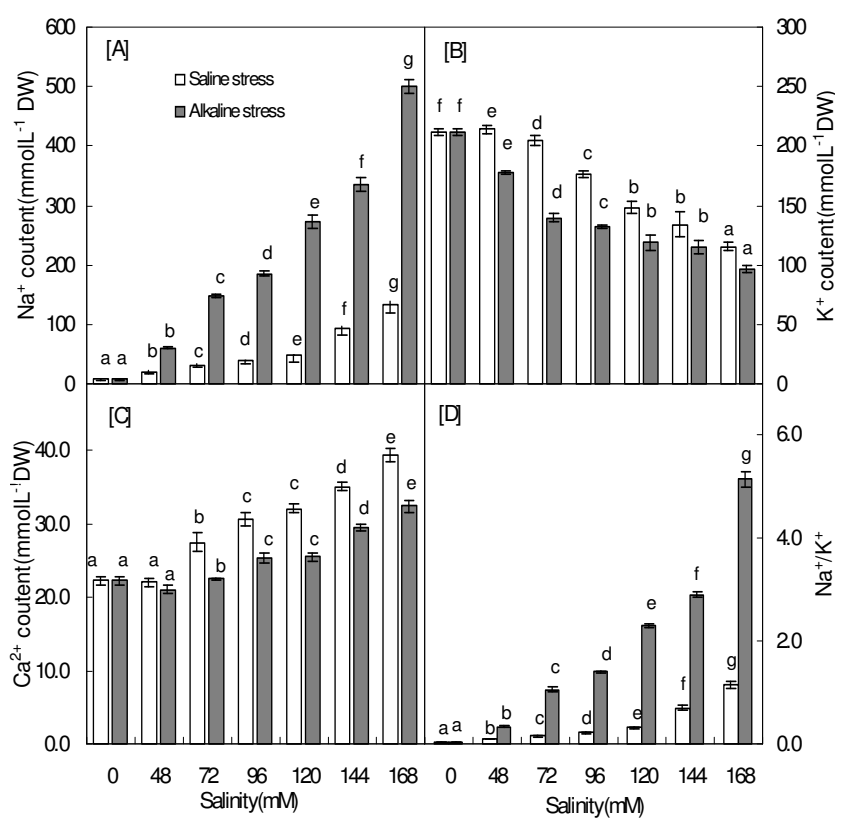

Fig. 6. Effect of salt and alkali stresses on $\mathrm{Na}+(\mathrm{A}), \mathrm{K}+(\mathrm{B}), \mathrm{Ca}_{2}+(\mathrm{C})$, $\mathrm{Na}+/ \mathrm{K}+(\mathrm{D})$ in shoots of oat seedlings, the 4 week-old oat seedlings were treated with salt stress $\left(\mathrm{NaCl}_{\mathrm{Na}} \mathrm{NO}_{4}=2: 1 ; \mathrm{pH} 7.03-7.29\right)$ and alkali stress $\left(\mathrm{NaHCO}_{3}: \mathrm{Na}_{2} \mathrm{CO}_{3}=2: 1 ; \mathrm{pH} 9.84-10.61\right)$ for 9 days, the values are means $( \pm \mathrm{SE})$ of triplicate samples

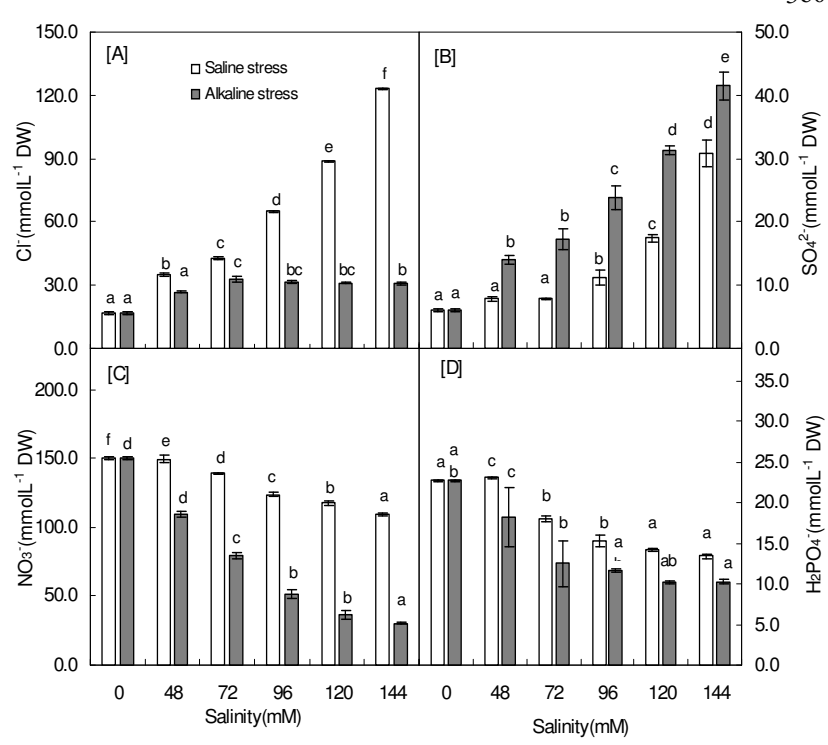

Fig. 7. Effect of salt and alkali stresses on $\mathrm{Cl}(\mathrm{A}), \mathrm{SO}_{4}^{2-}(\mathrm{B}), \mathrm{NO}_{3}^{-}(\mathrm{C})$, $\mathrm{H}_{2} \mathrm{PO}_{4}^{-}(\mathrm{D})$ in shoots of oat seedlings, the 4 week-old oat seedlings were treated with salt stress $\left(\mathrm{NaCl}: \mathrm{Na}_{2} \mathrm{SO}_{4}=2: 1 ; \mathrm{pH} 7.03-7.29\right)$ and alkali stress $\left(\mathrm{NaHCO}_{3}: \mathrm{Na}_{2} \mathrm{CO}_{3}=2: 1 ; \mathrm{pH} 9.84-10.61\right)$ for 9 days, the values are means $( \pm \mathrm{SE})$ of triplicate samples

Both of $\mathrm{NO}_{3} ; \mathrm{H}_{2} \mathrm{PO}_{4}$ contents decreased in saline and alkaline stresses, and the decrement in alkaline stress was greater than that in saline stress $(P<0.05$, Fig. $7 \mathrm{CD})$.

With the increasing salinity and alkalinity, proline content was obviously increased, and the increment was greater in alkaline stress than that in saline stress $(P<0.01$, Fig. 4A). The organic acid content kept unchanged in saline stress, but was obviously increased in alkaline stress $(P<0.05)$, which was 3.9 times than that of the control at the highest alkalinity (Fig. 4B).

\section{Discussion}

Inbibiting effect of saline and alkaline stresses on oat seedling growth

Biomass is comprehensive expression of plants responding to saline and alkaline stresses and also an accurate index of saline and alkaline resistance. Our results represented that low strength saline and alkaline treatments could promote growth of oat seedlings but high $\mathrm{pH}$ value had obvious inhibiting effect on growth $(P<0.01)$.

Generally, livability is representing for the selection of seedlings under environment. Alkaline salt inhibited the growth of oat seedlings, and can endanger the existence of plants. Different plant also has different saline or alkaline resistances. For same plant, its resistance to saline or alkaline is different in growth periods. Our result represented that livability decreased along with the increasing salinity and $\mathrm{pH}$ value in saline and alkaline stress, and the increasing alkaline strength had more visible effect on livability (Fig 1).

\section{Effects of saline and alkaline stresses on physiological changes of oat seedlings \\ Plasma membrane is the first protective screen for salt to enter cells, and is also the first part of plant organism to be}


361

suffered from saline or alkaline stress. As one of osmotic resistance indexes, the permeability of plasma membrane can directly represent the stability of plant cell for intracellular environment and adaptability and resisting ability for changes from extra-cellular environment. In this experiment, the conductivity increased with the increasing salinity, which was similar with the features of single alkaline salt stress (Shi and Yin, 1993, Shi and Zhao, 1997; Wang et al., 2009), and mixed saline-alkaline stress on Puccinellia tenuiflora, broomcom, wheat and Triticum aestivumAgropyron (Shi and Wang 2005; Shi and Sheng, 2005). The above stated that the greater the salinity was, the bigger the injury degree of membrane was. In the same salinity, the higher the $\mathrm{pH}$ value was, the more obvious the injury degree for membrane was $(P<0.05)$.

Under saline stress, the physiology of plants is disturbed because of insufficient water, absent mineral nutrition and inadequate energy. Cell membrane system and membrane structure were relative to photosynthesis, their broken directly or indirectly affected chlorophyll content, which causes decreasing of photosynthesis. In the end, the growth of plants is inhibited by not gaining adequate material and energy from photosynthesis. Generally, chlorophyll $a$ is helpful for absorb long wave light and chlorophyll $b$ is good for absorb short wave light. In the experiment, the total amount of chlorophyll was decreased under saline and alkaline stress, which inhibited growth of plants leading to decrease biomass (Yang et al., 2008).

Proline was an effective osmotic adjusting material of plants responding to stress situation (Song et al., 2006; Yang et al., 2008). Larger accumulation of proline represents stronger osmotic adjusting ability and resistivity for bad environment of plants (Yang et al., 2008). For example, the content of dissociative proline gradually increased by testing guineagrass and sunflower. The unique and chief factor of alkaline salt was high $\mathrm{pH}$ value, such as the stress factor of $\mathrm{Na}_{2} \mathrm{CO}_{3}$ for plants was high $\mathrm{pH}$ value but not osmotic stress and ion toxicity (Shi and Sheng, 1998; Shi et al., 1998). Under $\mathrm{Na}_{2} \mathrm{CO}_{3}$ stress, the content of dissociative proline in Puccinellia tenuiflora seedlings increased with the increasing salinity (Sun $e t$ al., 2000). The content of proline of the treated oat groups in this experiment was uniformly higher than that of the comparison group. With the increasing of salinity and $\mathrm{pH}$ value, the content of proline increased and the differences became remarkable (Fig. 4A), which stated that the osmotic ability and resistance for bad environment of Avena sativa were strengthen (Yang et al, 2009).

Organic acid normally exist in plant in organic anions formation, which not only neutralize excess cations (Yang et al., 2009), but also compensate loss of negative charge caused by nutrition deficiency and heavy metal stress (Zhang and $\mathrm{Mu}$, 2009). To balance excess $\mathrm{Na}^{+}$accumulation and compensate inorganic anion loss under alkaline stress (Fig. 45), oat seedlings adopted the response system of largely accumulating organic acid. The large accumulation of organic acid under alkaline stress and no accumulation under saline stress proved that organic acid might be a special response for high $\mathrm{pH}$ stress (Fig. $4 \mathrm{~B})$.

Alkaline stress might disturb selective adsorption of $\mathrm{K}^{+}-\mathrm{Na}^{+}$ that leads to unbalance of $\mathrm{K}^{+}-\mathrm{Na}^{+}$in cells (Yang et al., 2008). Normally, saline stress could inhibit plants for absorbing cations such as $\mathrm{Ca}^{2+}$. But in our experiment, the content of $\mathrm{Ca}^{2+}$ slightly increased, which might be the special response of oat to saline and alkaline stresses. Halophyte often accumulates inorganic anions such as $\mathrm{Cl}, \mathrm{SO}_{4}^{2-}$ in saline stress and reduces $\mathrm{NO}_{3}^{-}, \mathrm{H}_{2} \mathrm{PO}_{4}$ to keep the balance of cations and anions (Yang et al., 2007, 2008). Oat seedlings accumulated $\mathrm{Cl}^{-}$and $\mathrm{SO}_{4}^{2-}$ largely, which represented that the salt resistance mechanism of oat was nearly the same with that of halophyte. Alkaline stress visibly inhibited the accumulation of $\mathrm{Cl}^{-}$but irritated accumulation of $\mathrm{SO}_{4}^{2-}$ in high $\mathrm{pH}$ alkaline stress, the absorption of anions such as $\mathrm{NO}_{3}, \mathrm{H}_{2} \mathrm{PO}_{4}$ of halophyte was inhibited (Yang et al., 2008), which stated that the inhibitions for anion types of Avena sativa and halophyte in alkaline stress were different and the mechanism thereof needed future research.

Alkaline stress visibly irritated accumulation of $\mathrm{Cl}^{-}$and $\mathrm{SO}_{4}^{2-}$, and similar with halophyte that high $\mathrm{pH}$ also inhibited the absorption of $\mathrm{NO}_{3}, \mathrm{H}_{2} \mathrm{PO}_{4}^{-}$(Yang et al., 2008). This result stated that there was a different anion adjustment mechanism between Avena sativa and halophyte under alkaline stress that need further investigation.

\section{Alkaline resistant mechanism of oat seedlings}

The key point of why the effect of alkaline stress was higher than saline stress was that high $\mathrm{pH}$. One way for plants to adapt to high $\mathrm{pH}$ was to accumulate micromolecule metabolite with buffering function (such as organic acid, proline etc.) for adjusting internal $\mathrm{pH}$ value. Adjusting $\mathrm{pH}$ value was a process of consuming energy, which lowered intracellular $\mathrm{pH}$ and inhibited growth of plants simultaneously. Plants adjusted intracellular $\mathrm{pH}$ by adjusting micro-environment $\mathrm{pH}$ around root to keep relative balance of metabolism and ions. Plants can adjust $\mathrm{pH}$ in micro-environment outside roots by excreting $\mathrm{H}^{+}$, organic acid and discharging $\mathrm{CO}_{2}$ through respiration (Wang et al., 2009). Intracellular $\mathrm{pH}$ can be adjusted mainly by accumulating organic acid largely in vacuoles (Shi and Sheng, 2005). The large accumulation of organic acid in cells of oat seedlings under alkaline stress can compensate water and adjust intracellular $\mathrm{pH}$. Therefore, it was stated that accumulating organic acid in large amount was a physiological response mechanisms of oat to the alkaline stress.

The serious damage of alkaline stress on photosynthetic pigments and membrane system represented that alkaline stress might affect cytoplasm, which might break structure and functions of chloroplast and reduce synthesis of chlorophyll (Yang et al., 2007). Alkaline stress disturbed balance of inorganic ions, promoted absorption of $\mathrm{Ca}^{2+}$ and $\mathrm{Na}^{+}$and inhibited accumulation of $\mathrm{K}^{+}$, and decreased contents of $\mathrm{NO}_{3}$, $\mathrm{H}_{2} \mathrm{PO}_{4}^{-}$and accumulated $\mathrm{SO}_{4}^{2-}$ largely. The above two points seemed to indicate that alkaline stress might seriously disturb metabolism of $\mathrm{SO}_{4}^{2-}, \mathrm{NO}_{3}^{-}, \mathrm{H}_{2} \mathrm{PO}_{4}$, and the accumulation of both proline and organic acid under alkaline stress might be irritability response for the disturbance.

\section{Acknowledgments}

This work was supported by the Fundamental Research Funds for the central universities (DL12BA32, 2572014EA04), the National '973' Programme (2015CB150801), and was also funded by National Natural Science Foundation of China $(31172259,31370432)$. 


\section{References}

Li CL, Zhou H, Zhang GF, Zhang YJ, Meng L (2004) Effects of saline stress on germination of leafiness Alfalfa seeds. Chinese J Grassland 26:21-25.

Lutts S, Kiner, Bouharmont J (1996). NaCl-induced senescence in leaves of rice (Oryza sativa L.) cultivars differing in salinity resistance. Ann Bot 78:389-398.

Shi D, Sheng Y (2005). Effects of various salt-alkali mixed stress conditions on sunflower seedings and analysis of their stress factors. Environ Exp Bot 54:8-21.

Shi D, Wang DL (2005). Effects of various salt-alkaline mixed stresses on Aneurolepidium chinense (Trin.) Kitag. Plant and Soil 271:15-26.

Shi DC, Sheng YM (1998). Manual simulation of compound saline-alkaline ecological condition and effect on growth of guineagrass. Acta Botanica Sinica 40 (12):1136-1142.

Shi DC, Sheng YM, Zhao KF (1998). Simulation of complex Alkali-saline conditions and their effects on the growth of Chinese seedlings. Acta Pratacult Sinica 1:36-41.

Shi DC, Yin LJ (1993). Difference between salt ( $\mathrm{NaCl})$ and alkaline $\left(\mathrm{Na}_{2} \mathrm{CO}_{3}\right)$ stresses on Puccinellia tenuiflora (Griseb.) Scribn. et Merr. Plants. Acta Bot Sin 35:144-149 (in Chinese with English abstract).

Shi DC, Zhao KF (1997). Effects of sodium chloride and carbonate on growth of Puccinellia and on present state of mineral elements in nutrient solution. Acta Pratacult Sin 6:51-61 (in Chinese).
Song J, Feng G, Tian C.Y, Zhang FS (2006). Osmotic adjustment traits of Suaeda physophora, Haloxylon ammodendron and Haloxylon persicum in field or controlled conditions. Plant Science 170:113-119.

Sun GR, Yan XF (2000). Effect of $\mathrm{Na}_{2} \mathrm{CO}_{3}$ stress on content of free amino acid of Puccinellia tenuiflora seedling. Plant Research 20:71-72.

Tanic KK (1990). Agricultural salinity assessment and management. Society of Civil Engineers, New York 3-5.

Wang YX, Zhang B, Wang T (2009). Effects of saline stress on chlorophyll, bataine content and cell membrane permeability of alfalfa. Practa Science 26:53-56.

Yang CW, Chong J, Kim C, Li CY, Shi DC, Wang DL (2007). Osmotic Adjustment and ion balance traits of an alkali resistant halophyte Kochia sieversiana during adaptation to salt and alkali conditions. Plant Soil 294:263-276.

Yang CW, Shi DC, Wang DL (2008). Comparative effects of salt stress and alkali stress on growth, osmotic adjustment and ionic balance of an alkali-resistant halophyte Suaeda glauca (Bge.). Plant Growth Regul 56:179-190.

Yang CW, Zhang ML, Liu J, Shi DC, Wang DL (2009). Effects of buffer capacity on growth, photosynthesis, and solute accumulation of a glycophyte (wheat) and a halophyte (Chloris virgata). Photosynthetica 47:55-60.

Zhang JT, Mu CS (2009). Effects of saline and alkaline stresses on the germination, growth, photosynthesis, ionic balance and antioxidant system in an alkali-tolerant leguminous forage Lathyrus quinquenervius. Soil Science and Plant Nutrition 55:685-697. 